\title{
A Study of the Relationship between Personality Traits and Music Preference
}

\author{
Biaknungi $^{*}$ \\ Sampurna Montfort College, Bangalore, Karnataka, India \\ Received 09 March 2019, Accepted 11 May 2019, Available online 13 May 2019, Vol.7 (May/June 2019 issue)
}

\begin{abstract}
Music occupies a very important role in our lives. Music has been so helpful in many different ways; it has helped in changing our moods and also helped many to express themselves better through music. Music in India has undergone vast changes over generations. Since Vedic times, Indians were required to accurately recite the Vedas. This accuracy in recitation was essential as the Vedas were, in those days, transmitted through memory - Smriti and were learnt through hearing -Shruti. The kind of an emphasis applied on recitation and the right pronunciation lead to studies in phonetics and sound manipulation. The traditional Mizo musical instruments are very simple and crude in comparison to other Indian musical instruments and very out-dated to Modern Musical instruments. They can broadly be divided into three: Beating or Striking instruments; Wind instruments and String instruments. Using the Pearson"s product movement correlation analysis, the four dimensions of music genres under the Short Test of Music Preferences Scale (STOMP) Reflexive and Complex, Intensive and Rebellious, Upbeat and Conventional and Energetic and Rhythmic and the big five personality traits were evaluated
\end{abstract}

Keywords: Music, India, Mizo, Pearson Correlation, Neuroticism, Extraversion, Openness to Experience, Agreeableness, Conscientiousness

\section{Introduction}

Music occupies a very important role in our lives. Music has been so helpful in many different ways; it has helped in changing our moods and also helped many to express themselves better through music. From an alarm clock to a candlelight dinner, music enchants our mundane days. It is a language that speaks to every individual. It transcends any form of communication through the essence of a song. In Mayan civilization, music was a necessary element to celebrate a victory at war and even during the burial of prevalent personalities (Negrin, n.d.). Research has found that an average person listens to music $14 \%$ of the day (Veltri, 2010). Music is a fortunate accident that has evoked a realm of emotions. Lonsdale and North (2010) conducted a survey on the reasons behind listening to music. They found six reasons as to why people listen to music- to understand the state of the world, personal identity, interpersonal relationships, negative mood management, diversion and positive mood management. Perhaps, music has been looked at as providing mere emotional assistance for the past decades. It can gratify needs that are beyond the social and emotional context.

Corresponding author's ORCID ID: 0000-0003-1027-258X

DOI: https://doi.org/10.14741/ijmcr/v.7.3.8
Music in India has undergone vast changes over generations. Since Vedic times, Indians were required to accurately recite the Vedas. This accuracy in recitation was essential as the Vedas were, in those days, transmitted through memory - Smriti and were learnt through hearing -Shruti. The kind of an emphasis applied on recitation and the right pronunciation lead to studies in phonetics and sound manipulation. This was the origin of Indian Musical Raga-metre and Swaras - rhymes (Sudheer, n.d.). By tradition, vocal music in India has been attributed to devotional music, also known as Bhakti geet and musicians practiced music in temples in order to play tributes to the deity and the devotees. "The Bhakti form of worship gave revival to Indian Music in which the worship by prayers and by songs was stressed which were the sign of real devotion to the gods" (Naqvi \& Mohmand, 2011, p. 48).

From time immemorial, Mizo have been using different musical instruments. Even though we cannot date the origin, the "Mizo of Kabaw valley during late 10 th to 13 th century $A D$ had developed their music as nearly as they have done today". The traditional Mizo musical instruments are very simple and crude in comparison to other Indian musical instruments and very out-dated to Modern Musical instruments. They can broadly be divided into three: Beating or Striking instruments; Wind instruments and String instruments. 
After the Wales missionaries came to Mizoram, Mizo culture as a whole became more influenced by the West. This also includes music. In church, western instruments like piano, drums were incorporated during worship service which has never been done before. Looking at the current music scenario in Mizoram, we can see how Mizo traditional music is influenced by western music by the different bands, their music style and genres and how this has been a great influence among the younger population in the Mizo culture.

\section{Significance and Rationale for the study}

For many people, music plays a very important part in their lives. Many studies have shown that there is a relationship between our music preference and our personality. Rentfrow and Gosling( 2003), found that not only is music one of the most frequently occurring activities that people engage in, but people consider it important to them, not only as a hobby, but as a pertinent insight into their own personalities. The present study wants to explore the relationship between the two among the Mizo population and this will be the first of its kind to be conducted in the state of Mizoram, North Eastern part of India.

\section{Research Objective}

1) To measure personality traits through Big Five

2) To find preferences for different genres of western music using Short Test of Music Preference

\section{Hypothesis}

There is no relationship between music preference i.e reflective and complex, intense and rebellious, upbeat and conventional, energetic and rhythmic and big five personality traits.

\section{Review of Related study}

\section{Influence of Cattell}

Music acts as a key in facilitating an individual"s identity as it offers a sense of oneself as well as others. Music helps in the conception of identity through experiences and thus "enable individuals to place themselves in imaginative cultural narratives" (Sigg, 2009, p. 16). Additionally, it is also believed that people form an emotional attachment with the artists as well. An individual"s innate ideas, thoughts, attributes and morals can be portrayed through the art of music.

The extensive journey of music and personality traits can be dated back to 1953 when Cattell proclaimed the value of music in identifying various unconscious personality factors that may have been intentionally or unintentionally ignored by standardized inventories. Cattell and Anderson (1953) created the Institute for
Personality and Ability Testing (IPAT) music preference test which included 120 excerpts of classical and jazz music. They correlated the IPAT music preference test with Cattell"s 16 Personality Factor Questionnaire. They found that several of the personality factors correlated with music preference (Juslin \& Sloboda, 2011).

Further, Cattell and Saunders (1954) played 120 excerpts of 20 seconds to 188 mental hospital people and 196 normal subjects. They extended the test using factor analysis, established 11 substantial music-preference factors, each of which determined an unconscious reflection of distinct personality traits (Hargreaves, 1986). These factors were used to compare normal and abnormal types of personality in order to construct an incremental personality inventory for psychiatric diagnoses. (Veltri, 2010). "For example, musical excerpts with fast tempos defined one factor, labeled Surgency, and excerpts characterized by melancholy and slow tempos defined another factor, labeled Sensitivity" (cited in Rentfrow \& Gosling, 2003, p. 1237. However, because they were mainly interested in using the IPAT to examine the dimensions of the $16 \mathrm{PFQ}$, their publication does not provide the specific music preference categories (Juslin \& Sloboda, 2011).

For about 30 years, research in this particular area remained stagnant until Litle and Zuckerman (1986) developed the Music Preference Scale (MPS) in the context of sensation seeking experiences. Sensation seeking is a personality trait that is defined as "varied, novel, complex and intense, and by the readiness to take physical, social, legal, and financial risks for the sake of such experiences" (cited in Arnett, 1993, p. 289). The MPS requires subjects to rate how they like particular styles of music. Sensation seeking correlated positively with all types of rock music and negatively with bland film and television soundtrack music (Langmeyer, 2012).

Indian culture and tradition has been flourishing since thousands of years. The highly diverse resources and aesthetics enriches the forthcoming generations time and again. However, in the past few decades, the idea of Indian ethics has incorporated the norms of the West. The vast cultural gap between the East and the West is slowly diminishing.

In 2002, Saldanha explores the influence of Globalization and Westernization on the youth of Bangalore. He argues that Bangalore is the city "where the struggle for the definition of the future is most felt" (cited in Saldanha, 2002, p. 339). He divides the Third World India into youth who are translocal, meaning they inculcate both local as well as global ethnicities and the „local others" who perceive globalization as a threat. In this regard, Western pop music has expanded the translocality among the youth in India, particularly Bangalore.

Every Society has its own traditional music and in every society, folk music is as old as the age of that society. Some Indian cultures have very long musical histories; but Mizo culture does not have such history. Yet 
the origin of Mizo Music is a mystery. It is therefore, difficult to trace the origin, and to arrange the chronological sequences of the heritage of Mizo Music. However, we have seen some couplets are developed during the settlement of Thantlang in Burma estimated between 1300-1400 AD. (Thanmawia,2018). Most of the traditional Mizo musical instruments have also been changed or modified like the western instruments. Looking at the current music scenario in Mizoram, we can see how Mizo traditional music is influenced by western music by the different bands, their music style and genres and how this has been a great influence among the younger population in the Mizo culture.

\section{Research Design}

The present study is a descriptive type of research. The study aimed to determine the relations between two variables - music preferences and personality traits. Hence, a correlational method of design was used.

\section{Participants}

The study included 60 Mizo between the ages of 18 to 30, who consider listening to music as a very important part of their lives. The participants consist of 30 males and 30 females. Currently, they are all residing in Bangalore and their education ranges from 10th standard to MPhil. Some of them are working presently whereas some of them are still pursuing their studies

\section{Inclusion criteria}

1) Individuals who consider music to be a significant part of their lives.

2) Individuals who prefer western music over Indian music.

3) Participants have to be Mizo.

4) Individuals between the ages of 18 to 30 .

5) Individuals who are currently living in Bangalore

\section{Exclusion criteria}

1) People who are not exposed to music

2) Persons with mental illness

3) Non English speaking

\section{Tool: Short Term Music Preference Scale (STOMP).}

1. Informed consent form: The informed consent form was used to obtain permission from the students for data collection. The form included the purpose of the study, phases of data collection, and a guarantee of anonymity and confidentiality of all information given. Since the sample included minors, parental consent was also offered.

2. Short Test of Music Preferences (STOMP): It was devised by Rentfrow and Gosling in 2003, was used to measure music preferences is used in the present study

\section{Procedure of data Collection}

Preliminary phase: Data was collected from different Mizo population residing in Bangalore. STOMP, Neo-FFi, the informed consent and the demographic sheet form were given to the participants.

Secondary phase: Rapport was established with the participants and the purpose of the study was explained. After the participants signed the Informed Consent Form volunteering to participate in the study committedly and without compensation, the study was conducted. To collect the required data, the demographic sheet, STOMP and Neo-Ffi was administered to them. The scale was administered to them as per the manual of the test. General instructions included that all information would be kept confidential; all items of the scale must be answered as honestly and as carefully as possible.

Final phase: The obtained data was scored according to the STOMP and Neo-Ffi-manual. The inclusion criteria was fulfilled.

\section{Data Analysis}

After data collection and scoring, results were tabulated and analyzed using IBM SPSS Statistics 20 software. Pearson"s correlation and independent sample t-test was used.

\section{Ethical Considerations}

1. The objectives and purpose of the study was communicated to the participants.

2. A consent form duly signed by the participants was collected prior to the administration of the test.

3. The data was kept confidential and subjects were assured of confidentiality.

4. The questionnaires did not contain any degrading or discriminating data.

\section{Demographic detail of the participants}

In the study, there were 60 participants, among which 30 were males and 30 were females. The age of the participants ranges from 18 to 30 . All the participants are Mizo who reside in Bangalore. Their occupation ranges from 10th standard to M.Phil.

Table 1 Mean and standard deviation of the age of the participants

\begin{tabular}{|c|c|c|}
\hline Number of Participants & Mean of Age & Standard Deviation \\
\hline 60 & 23.4 & 2.67 \\
\hline
\end{tabular}

As seen in table 4.1, the average age of the participants is 23.4 years and the standard deviation is 2.67. The study intended to emphasise on Mizo people in the age range of 18 to 30 . 
Table 2 Correlation of Music Preference and Personality

\begin{tabular}{|c|c|c|c|c|c|}
\hline Personality Traits & Pearson Correlation & $\begin{array}{l}\text { Intense and } \\
\text { Rebellious }\end{array}$ & $\begin{array}{l}\text { Reflective and } \\
\text { Complex }\end{array}$ & $\begin{array}{l}\text { Upbeat and } \\
\text { Conventional }\end{array}$ & $\begin{array}{l}\text { Energetic and } \\
\text { Rhythmic }\end{array}$ \\
\hline \multirow[t]{2}{*}{ Neuroticism } & Pearson Correlation & .063 & -.066 & .125 & .095 \\
\hline & Sig. (2-tailed) & .632 & .618 & .341 & .472 \\
\hline \multirow[t]{2}{*}{ Extraversion } & Pearson Correlation & -.134 & -.044 & .154 & -.168 \\
\hline & Sig. (2-tailed) & .307 & .740 & .241 & .200 \\
\hline \multirow[t]{2}{*}{ Openness to Experience } & Pearson Correlation & -.012 & .094 & .126 & -.112 \\
\hline & Sig. (2-tailed) & .930 & .475 & .336 & .394 \\
\hline \multirow[t]{2}{*}{ Agreeableness } & Pearson Correlation & .110 & -.055 & .106 & -.107 \\
\hline & Sig. (2-tailed) & .401 & .678 & .418 & .416 \\
\hline \multirow[t]{2}{*}{ Conscientiousness } & Pearson Correlation & -.166 & .094 & -.116 & .027 \\
\hline & Sig. (2-tailed) & .206 & .475 & .376 & .837 \\
\hline
\end{tabular}

Using the Pearson"s product movement correlation analysis, the four dimensions of music genres under the Short Test of Music Preferences scale (STOMP) - Reflexive and Complex, Intensive and Rebellious, Upbeat and Conventional and Energetic and Rhythmic and the big five personality traits were evaluated. The STOMP scale was devised by Rentfrow and Gosling in 2003 to evaluate 23 genres of music. The NEO-FFI was formulated by Costa and McCrae in 1992 to measure the big five personality traits- Neuroticism, Extraversion, and Openness to Experiences, Agreeableness and Conscientiousness.

Reflexive and complex: The significance level between Extraversion and Reflexive and Complex is at 0.740 , with a negative correlation of -.044 , demonstrating that there is no significant correlation between the two. This suggests that individuals who listen to the mentioned music genres are not necessarily are talkative, out-going, gregarious, assertive, excitement seekers, warm, and friendly and have good leadership skills. This finding is supported by the previous studies as they have found no significant correlation between Extraversion and Reflexive and Complex dimension (Rentfrow \& Gosling, 2003). Openness to Experience was also to found to have no significant correlation (0.475) with Reflective and Complex dimension. It can be inferred that those who listen to genres that fall under this dimension have no correlation with being open to new experiences and vice versa. Their music preference has no correlation with their personality traits. The pioneers of the study Rentfrow and Gosling also found that Openness to Experience was positively correlated with Reflexive and Complex (Rentfrow \& Gosling, 2003).

In the present study, all personality traits have no significant correlation with reflective and complex music preference. This is a new finding as the previous studies only found that Neuroticism, Agreeableness and Conscientiousness have been found to have no significant correlation with the dimension. Neuroticism, in the Indian context has been found to be inversely correlated with women (Magan, Mehta, Sarvottam \& Pandey, 2014). This was seen in a recent study conducted by Magan, Mehta, Sarvottam and Pandey in 2014. It was noted that Neuroticism had a significant negative correlation with age in women during their middle age. It was also suggested that Neuroticism decreased with age (Magan, Mehta, Sarvottam \& Pandey, 2014).

Intense and rebellious: This dimension consists of genres namely, Rock, Alternative, Punk and Heavy metal. The sound of rock is conventionally emphasized on electric guitar and percussion instruments combining drums and cymbals. Alternative music originally emerged from the underground rock artists and independent music in the 1980s. It is heavily influenced by punk rock gothic music. This particular dimension is often associated to sensation seeking behaviour, aggression and impulsivity. In comparison to previous studies, none of the factors seem to show a significant correlation with the music dimension.

Upbeat and conventional: Upbeat and Conventional music includes Country, gospel, oldies, pop, religious and soundtracks/theme songs. This element of music focuses on a sense of acoustic rhythm- including pedal steel guitar and drums. Popular music involves eclectic music as well as dance elements. The results indicate no significant relationship between the dimension and the big five factors.

Energetic and rhythmic: Energetic music incorporates components of Funk, Dance/ Electronica, Rap/ Hip-hop, Reggae and Soul R\&B. This Hip/Hop culture became increasingly popular as block parties in US escalated in 1970s. The African-American youth were especially passionate about funk, disco, soul and dub music. These genres are related to fast-paced energetic rhythms associated with elevated moods. The findings suggest that there is no significant correlation with the five factors.

In the present study, we find that there is no significant correlation between music preference and the big five factors. Some of the reasons can be laid out as a plausible explanation. During data collection, some of the doubts that the participants were facing was that they did not know some of the music genres, in the sense, they were not aware that the particular type of music was called, for example "bluegrass". This may have been interference in the study to find out the relationship between the two factors. The participants are also not 
representative of the entire Mizo population as there are only limited participants, hence we cannot say that there is no correlation between Music Preference and personality among the Mizo Population.

Further, the scale was standardized on a western population; the study may not have held an objective value for understanding music and personality. Another interesting point would include the very fact that although Indian adolescents are heavily influenced by western music, the impact of indigenous music is inevitable. Culture, here plays a fundamental role as Indians are bound to be affected by its extensive cultural history, specifically music. On a personal note, it can be inferred that indigenous music is an integral part of an individual's life.

The findings imply that Music is a far-reaching concept and it requires meticulous knowledge and comprehension in order to acquire closure. The study confirms to the hypothesis that there is no association between Music preferences and Personality traits. However, it needs further research to embellish the very art of understanding music and its relation to an individual's personality.

It can be concluded thatmajor finding of the study was that there is no correlation between music preference and personality. The study also found that gender difference exists among some of the dimensions of music preference and personality. Although this is the finding of the study, we cannot come to a conclusion that Personality and Music Preference does not have any correlation as the sample is not representative of the entire population

\section{Recommendations and Suggestions}

1. The study can be better and broadened by increasing the participants.

2. Various differences in the groups within the age range can be further studied

3. Other variables can be added to study the relationship between music preference and personality.

4. Recommended to incorporate Indian music genres.

\section{References}

[1]. Aristotle on music. (n.d.). Politics book VIII, chap. 5-7. Retrieved from htpp://faculty.smu.edu/jkazez/ mo109/AristotleOnMusic.htm

[2]. Arnett, J. (1993). Sensation seeking: A New Conceptualisation and a New Scale. Elsevier Science Ltd.16, No. 2, pp 289-296. 0191-8869/94

[3]. Chamorro-Premuzic, T. \& Furnham, A. (2007). Personality and music: Can traits explain how people use music in everyday life? British Journal of Psychology. 98, 175-185.

[4]. Collingwood, J. (n.d.). Preferred music style is tied to personality. Retrieved from

[5]. http://psychcentral.com/lib/preferred-music-style-is-tiedto-personality/

[6]. Cooper, C.L. \& Pervin, L.A. (1998). Personality. Psychology Press. ISBN 0415135044. Delsing, M.J., Bogt, T.F., Engels,
R.C., \& Meeus, W.H. (2007). Adolescents" music preferences and personality characteristics. European Journal of Personality. 22: 109-130. doi: 10.1002/per.665

[7]. Digman, J.M. (1990). Personality structure: Emergence of the Five-Factor Model. Annu. Rev. Psychol. 41:417-40. Dollinger, S.J. (1993). Personality and music preference: Extraversion and excitement seeking or openness to experience? Psychology of Music. 21: 73 doi: $10.1177 / 030573569302100105$.

[8]. Fleming, J. (2006). Traits, types, and temperament in personality development. Retrieved from http://swppr.org/Textbook/Ch\%2014\%20Traits.pdf

[9]. Indian Music. (n.d.). Cultural India. Retrieved from http://www.culturalindia.net/indianmusic

[10]. George, D., Stickle, F., Rachid, F., The association between types of music enjoyed and cognitive, behavioral and personality factors of those who listen. Psychomusicology, 19(2), 32-56

[11].Juslin, P.N. \& Sloboda, J. (2010). Handbook of music and emotion: Theory, Research, Applications. Oxford University Press

[12].Lester, D., \& Whipple, M. (1996). Music preference, depression, suicidal preoccupation, and personality: comment on Stack and Gundlach"s papers. Suicide and LifeThreatening Behavior. 26, Issue 1, pages 68-70

[13]. Lonsdale, A.L. \& North, A.C. (2010). Why do we listen to music? A uses and gratifications analysis. British Journal of Psychology. 102 (1).

[14]. Magan, D., Mehta, M., Sarvottam, K., YadaV, R., \& Pandey, R. (2014). Age and gender might influence big five factors of personality: A preliminary report in Indian population. Indian J Physiol Pharmacol. 58(4) : 381-388

[15]. Majumdar, R. (2010). Consumer behaviour: insights from Indian market. PHI Learning Pvt. Ltd. Retrieved from https://books.google.co.in/books?id=RsjcPBrKjP4C\&printse $c=$ frontcover\&source=gbs_ge_summary_r\&cad=0\#v=onepa ge \&q\&f=false.

[16]. McCrae, R. R. \& John, O. P. (1992). An Introduction to the Five-Factor model and its applications. Journal of Personality. 60: 175-215. doi 10.1111/j.14676494.1992.tb00970.x.

[17]. Miranda, D. (2012). The role of music in adolescent development: much more than the same old song. International Journal of Adolescence and Youth. 18, Issue 1.

[18]. Naqvi, R.H. \& Mohmand, M.I. (2011). Cultural History of Indian subcontinent; with special reference to Arts and Music. Journal of Law and Society. 41 (57 \& 58). Retrieved from https://www.academia.edu/ 9320350/Cultural_ History_Of_Indian_Su

[19]. Bcontinent_With_Special_Reference_To_Arts_And_Music

[20]. Negrin, D. (n.d.). The Importance of music in your life. Retrieved from Piano around the world: http://www.pianoaround.com/the-importance-of-musicin-your-life/

[21]. North, A.C., \& Hargreaves, D.J. (1999). Music and adolescent identity. Music Education Research, 1(1), 75-92.

[22]. Pavitra, KS., Chandrashekar, CR., Choudhury, P. (2007). Creativity and mental health: A profile of writers and musicians. Indian J Psychiatry. 49(1)

[23]. Prokhorov, V. (2005). „I want to make the world better." The Guardian. Retrieved from http:// www.theguardian.com/music/2005/jul/15/classicalmusica ndopera2

[24]. Rawlings, D., \& Ciancarelli, V. (1997). Music preference and the five-factor model of the NEO personality inventory. Psychology of Music, 25, $120-132$. 
[25]. Rentfrow, P.G. \& Gosling, S.D. (2003). The Do Re Mi"s of Everyday Life: The Structure and Personality Correlates of Music Preferences. University of Texas at Austin.84:

[26]. 6, 1236-1256.

[27]. Rentfrow, P.G., \& Gosling, S.D. (2007). The content and validity of music-genre stereotypes among college students. Society for Education, Music and Psychology Research. 35(2). 306-326. doi: 10.1177/ 0305735607070382

[28]. Richards, M. Mus, M. \& S.R.C. (2009). Pythagoras and music. Rosicrucian Digest. 3033

[29]. Robb, A. (2014). Why do people care less about music as they grow older? Retrieved from www.newsrepublic.com.

[30]. Saldanha, A. (2002). Music, space, identity: geographies of youth culture in Banglaore. Cultural Studies. 16(3), 337350.

[31]. Sudheer. (n.d.). Ancient Hindu Culture. Crystal links. Retrieved from http://www.crystalinks.com /indiaculture. html
[32].Sigg, N. (2009). An investigation into the relationship between music preference, personality and psychological wellbeing. Auckland University of Technology. Retrieved from http://aut.researchgateway.ac.nz /bitstream/ handle/10292/955/SiggN.pdf;jsessionid =A12EDD9E7 C5 CC5A3D385935B57C7153F?sequence $=4$

[33]. Tully, D. Examining the Relationship between Music Preference and Personality Type. Retrieved from http://esource.dbs.ie/bitstream/handle/10788/420/ba_tull y_d_2012.pdf?sequence $=1$

[34].Tekman, H.G. and Hortaçsu, N. (2003). Perceiving and reasoning about music styles and their listeners: The role of Social Identity. Proceedings of the 5th Triennial ESCOM Conference.

[35].Veltri, T.M. (2010). Personality Correlates of Preferences for Music Structure and Emotion. The University of Sheffield.

[36].Zweigenhaft, Richard L. (2008) A do re mi encore: A closer look at the personality correlates of music preferences. Journal of Individual Differences. Vol 29(1), 4555 